\title{
Clinical response after chitosan microparticle administration and preliminary assessment of efficacy in preventing metritis in lactating dairy cows
}

\author{
R. Daetz, ${ }^{*}$ F. Cunha, ${ }^{*}$ J. H. Bittar, ${ }^{* 1}$ C. A. Risco, ${ }^{*}$ F. Magalhaes,† Y. Maeda,ł J. E. P. Santos,§ K. C. Jeong,§\# \\ R. F. Cooke,ll and K. N. Galvão* $\|^{2}$ \\ *Department of Large Animal Clinical Sciences, College of Veterinary Medicine, University of Florida, Gainesville 32610 \\ †School of Veterinary Medicine and Animal Sciences, University of São Paulo, São Paulo, SP 05508 270, Brazil \\ $\ddagger$ School of Veterinary Medicine, Kitasato University, Towada, Aomori, 034-8628, Japan \\ §Department of Animal Sciences, College of Agricultural and Life Sciences, University of Florida, Gainesville 32610 \\ \#Emerging Pathogens Institute, University of Florida, Gainesville 32610 \\ \|Eastern Oregon Agricultural Research Center, Oregon State University, Burns 97720 \\ TD. H. Barron Reproductive and Perinatal Biology Research Program, University of Florida, Gainesville 32610
}

\begin{abstract}
The objectives were to evaluate the clinical response to intrauterine administration of chitosan microparticles $(\mathrm{CM})$ and to assess efficacy for preventing metritis in dairy cows. Holstein cows $(\mathrm{n}=104 ; 40$ primiparous and 64 multiparous) at increased risk for metritis (cows that had abortion, dystocia, twins, stillbirth, or retained placenta) were randomly assigned to 1 of 2 treatments at $1 \mathrm{~d}$ in milk (DIM; $24 \mathrm{~h}$ postpartum): CM group (n $=52$ ), daily intrauterine infusion of $8 \mathrm{~g}$ of $\mathrm{CM}$ dissolved in $40 \mathrm{~mL}$ of sterile water for $5 \mathrm{~d}$; control (CON) group $(\mathrm{n}=52)$, daily intrauterine infusion of $40 \mathrm{~mL}$ of sterile water for $5 \mathrm{~d}$. Clinical response was assessed by evaluation of parameters associated with inflammation (rectal temperature and plasma haptoglobin concentration) and metabolism [plasma nonesterified fatty acid (NEFA) and $\beta$-hydroxybutyrate (BHB) concentrations] up to 14 DIM, and daily milk yield up to 30 DIM. Uterine discharge $\mathrm{pH}$ was evaluated at $4,7,10$, and 14 DIM as an indicator of bacterial load and acid byproduct production. The cumulative incidence of metritis was evaluated up to 4, 7, 10, and 14 DIM. Continuous and dichotomous outcomes were evaluated with mixed linear and logistic regression analysis, respectively. Treatment with CM did not affect rectal temperature $\left(39.17 \pm 0.04\right.$ vs. $\left.39.14 \pm 0.04^{\circ} \mathrm{C}\right)$, haptoglobin $(1.10 \pm$ 0.05 vs. $1.07 \pm 0.05 \mathrm{mg} / \mathrm{mL})$, NEFA (0.64 \pm 0.04 vs. $0.63 \pm 0.04 \mathrm{mmol} / \mathrm{L}), \mathrm{BHB}(0.61 \pm 0.03$ vs. $0.57 \pm 0.03$ $\mathrm{mmol} / \mathrm{L})$, or milk yield $(30.3 \pm 0.92$ vs. $30.1 \pm 0.97$ $\mathrm{kg} / \mathrm{d}$ ) compared with CON. An interaction between treatment and time showed that NEFA concentrations
\end{abstract}

\footnotetext{
Received May 4, 2016.

Accepted July 15, 2016.

${ }^{1}$ Current address: Department of Population Health, College of Veterinary Medicine, University of Georgia, Athens, GA.

${ }^{2}$ Corresponding author: galvaok@ufl.edu
}

were lower for CM than CON at 10 DIM $(0.46 \pm 0.06$ vs. $0.64 \pm 0.06 \mathrm{mmol} / \mathrm{L})$. Treatment with $\mathrm{CM}$ resulted in greater uterine discharge $\mathrm{pH}$ than $\mathrm{CON}$ (6.91 \pm 0.03 vs. $6.83 \pm 0.02$ ). Cows that developed metritis had increased concentrations of haptoglobin and BHB, and decreased uterine discharge $\mathrm{pH}$ and milk yield. Treatment with CM resulted in decreased incidence of metritis up to 7 DIM compared with CON (46.2 vs. $65.4 \%)$; however, no differences were found at 4 (11.5 vs. $17.3 \%), 10$ (61.5 vs. $73.1 \%$ ), and 14 DIM (63.5 vs. $73.1 \%$ ) for $\mathrm{CM}$ versus CON, respectively. In conclusion, $\mathrm{CM}$ did not alter clinical parameters of cows at risk for metritis, and may merit further investigation for prevention of metritis. However, the duration of treatment may have to be extended to effectively reduce the incidence of metritis during the high-risk period.

Key words: metritis, chitosan microparticles, dairy cow

\section{INTRODUCTION}

Contamination of the female reproductive tract following parturition is ubiquitous in dairy cows (Sheldon and Dobson, 2004; Jeon et al., 2015) leading to high prevalence $(\sim 20 \%)$ of metritis. The incidence of metritis in cows at increased risk for metritis such as cows that had dystocia, twins, retained placenta (RP), or stillbirth is $>50 \%$ (Markusfeld, 1984; Curtis et al., 1985; Martinez et al., 2012). Besides having welfare implications because of the pain associated with this condition (Stojkov et al., 2015), metritis leads to economic loss because of decreased milk yield, decreased fertility, and increased culling (Overton and Fetrow, 2008). Although uterine bacterial contamination is ubiquitous postpartum, Escherichia coli, Trueperella pyogenes, Fusobacterium necrophorum, and Bacteroides spp. are thought to be the main causative agents of metritis (Sheldon and Dobson, 2004; Bicalho et al., 2010; Jeon et al., 2015). 
Recent work has highlighted the importance of $E$. coli (Bicalho et al., 2010; Sheldon et al., 2010), especially the fact that $E$. coli predisposes to infection with other pathogenic bacteria such as $F$. necrophorum and $T$. pyogenes (Bicalho et al., 2012), increases the likelihood of developing metritis, and decreases the likelihood of pregnancy (Bicalho et al., 2010, 2012).

Third-generation cephalosporins are approved for treatment of metritis and have been used successfully to prevent metritis (Risco and Hernandez, 2003; McLaughlin et al., 2013). However, the US Food and Drug Administration has prohibited the use of thirdgeneration cephalosporins for prevention of disease in cattle. This prohibition was based on the risk to public health because of increased resistance of Salmonella to cephalosporin antibiotics, and the link to cephalosporin use in food animals. This action highlights the need for alternative antibiotics for prevention and treatment of disease in food animals, so we can protect human and animal health. Nonetheless, during the last 2 decades, research into discovering and developing new antibacterial agents has been limited (Courvalin, 2008). This antagonistic reality of increased antimicrobial resistance of bacteria and limited therapeutic availability of antibiotics will likely limit the options for prevention and treatment of metritis and other diseases.

Recent research from our group has demonstrated that chitosan microparticles (CM) can be a viable alternative to traditional antibiotics (Jeon et al., 2014). We demonstrated that $\mathrm{CM}$ acts by binding to structural components of the bacterial cell membrane and have a dose-dependent broad spectrum of antimicrobial activity (Jeon et al., 2014). Although CM work better at low $\mathrm{pH}$, they work well at neutral $\mathrm{pH}$, which is critical for activity in the lumen of organs. Indeed, we showed that intrauterine infusion of $8 \mathrm{~g} / \mathrm{d}$ of $\mathrm{CM}$ for $5 \mathrm{~d}$ was as effective as systemic treatment with $2.2 \mathrm{mg} / \mathrm{kg}$ of ceftiofur hydrochloride for $5 \mathrm{~d}$ at reducing the number of E. coli in the uterus (Jeon et al., 2014). Another important feature of $\mathrm{CM}$ is that they exert a broad spectrum of antimicrobial activity without increasing resistance (Ma et al., 2016), probably because it acts by binding to structural components of the bacterial cell wall (Jeon et al., 2014).

Although chitosan is categorized as GRAS (generally recognized as safe) for general use in foods by the Food and Drug Administration, no evaluation has been done of clinical response after intrauterine administration in cows. Therefore, one of the objectives of this study was to evaluate the clinical response after intrauterine administration of CM in dairy cows. We also hypothesized that intrauterine infusion of $\mathrm{CM}$ in cows at increased risk for metritis would decrease the incidence of metritis; therefore, the second objective was to evaluate the efficacy of intrauterine CM administration in preventing metritis in dairy cows.

\section{MATERIALS AND METHODS}

\section{Cows, Housing, and Feeding Management}

All animal procedures were approved by the University of Florida Institutional Animal Care and Use Committee (IACUC\# 201207405). This study was conducted in a 4,000 lactating-cow herd located in North Central Florida. A total of 104 (40 primiparous and 64 multiparous) Holstein cows at increased risk for metritis (cows that had abortion, dystocia, twins, stillbirth, or retained placenta were enrolled from January to April 2014. Cows were housed in free-stall barns and were milked 3 times daily. The rolling herd average milk production was approximately $11,000 \mathrm{~kg}$ of milk/cow per year. Cows were fed the same TMR, formulated to meet or exceed the NRC (2001) nutrient requirements for lactating Holstein cows weighing 680 $\mathrm{kg}$ and producing $45 \mathrm{~kg}$ of $3.5 \%$ FCM.

\section{Sample Size}

The outcome metritis incidence was used for sample size calculation because dichotomous outcomes typically have a larger variance and so require a larger sample than a similar effect size with a continuous outcome (Bhandari et al., 2002). The sample size was calculated to detect a difference of 17 percentage units ( 28 vs. $45 \%$ or 45 vs. $62 \%$ ) in metritis incidence because this was the weighted average reduction in metritis incidence when ceftiofur was used to prevent metritis in dairy cows at increased risk for metritis (Risco and Hernandez, 2003; McLaughlin et al., 2013). A sample size of 104 cows (52 per group) was calculated (Minitab Inc., State College, PA) for $\alpha=0.05$ and $\beta=0.20$, and allowing for up to $10 \%$ attrition. With this sample size, we would be able to detect a difference of $0.15 \mathrm{mmol} / \mathrm{L}$ in nonesterified fatty acids (NEFA), $0.15 \mathrm{mmol} / \mathrm{L}$ in BHB, or $0.15 \mathrm{mg} /$ $\mathrm{mL}$ in haptoglobin, with a standard deviation of $0.25, \alpha$ of $5 \%$, and power of $80 \%$.

\section{Inclusion and Exclusion Criteria}

Only cows with at least one risk factor for metritis (abortion, dystocia, twins, stillbirth, or retained placenta) were eligible for enrollment in the study. Abortion was defined as expulsion of a dead calf between dry off (220 d of gestation) and $260 \mathrm{~d}$ of gestation. Calving difficulty was scored using a scale from 1 to $5: 1=$ no assistance; 2 = assistance by one person without the use of mechanical traction; $3=$ assistance by 2 or more 
people; $4=$ assistance with mechanical traction; $5=$ fetotomy or cesarean section. Calving difficulty 2 to 5 were considered dystocia; however, cows with score 5 were not included in the study. Twins were defined as the birth of 2 calves. Stillbirth was defined as the birth of a dead calf after $260 \mathrm{~d}$ of gestation. Retained placenta was defined as failure to release the placenta within 24 $\mathrm{h}$ of parturition. The distribution of risk factors in each group is shown in Table 1. Cows with compromised general health status such as clinically lame cows, cows with displaced abomasum, pneumonia, Johne's disease, cancer, or any other debilitating condition were not included in the study.

\section{Treatment Assignment}

To achieve a balanced inclusion within parity, 2 enrollment lists were prepared, one for primiparous and another for multiparous cows. The first cow to be enrolled was allocated to 1 of the 2 treatment groups (CM or control, CON) by flipping a coin. The following cow to be enrolled was assigned to the opposite treatment group, and this scheme was followed systematically until the target sample size was reached. This scheme allowed for equal sample sizes between groups.

Cows in the CM group $(\mathrm{n}=52)$ received daily intrauterine infusion of $8 \mathrm{~g}$ of $\mathrm{CM}$ suspended in $40 \mathrm{~mL}$ of sterile water for $5 \mathrm{~d}$, starting at 1 DIM $(24 \mathrm{~h}$ after calving). Cows in the CON group $(\mathrm{n}=52)$ received daily intrauterine infusion of $40 \mathrm{~mL}$ of sterile water for $5 \mathrm{~d}$, starting at 1 DIM. An insemination pipette (Next Generation 30' Superflex Deep Horn Insemination pipettes, York, PA) was used to deliver the solution into the uterine lumen. The intrauterine infusions were performed after the vulva was cleaned using iodine scrub and $70 \%$ alcohol.

\section{Dosage and Treatment Period Determination}

The treatment dose of $8 \mathrm{~g} / \mathrm{d}$ was calculated to achieve a concentration of at least $0.2 \%$ of $\mathrm{CM}$ in the uterine lumen, assuming the uterus holds a volume of approximately $4 \mathrm{~L}$. Based on previous work, the volume of the uterus was estimated to be approximately $4 \mathrm{~L}$ (Gier and Marion, 1968; Mateus et al., 2002). The concentration of $0.2 \%$ of $\mathrm{CM}$ had been shown to be effective in eliminating intrauterine $E$. coli in vitro and the dose of $8 \mathrm{~g} / \mathrm{d}$ had been shown to be effective in eliminating intrauterine $E$. coli in vivo (Jeon et al., 2014). The treatment period was set to $5 \mathrm{~d}$ to mirror the treatment period recommendation for treatment of metritis using ceftiofur hydrochloride (Excenel, Zoetis, Madison, NJ) as performed in our previous study (Jeon et al., 2014).
Table 1. Distribution of risk factors for development of metritis by treatment group ${ }^{1}$

\begin{tabular}{llccc}
\hline \multirow{2}{*}{ Risk factor $^{2}$} & Level & $\begin{array}{c}\mathrm{CM}(\%) \\
(\mathrm{n}=532)\end{array}$ & $\begin{array}{c}\mathrm{CON}(\%) \\
(\mathrm{n}=52)\end{array}$ & $P$-value \\
\hline Parity & Primiparous & 38.5 & 38.5 & 1.00 \\
& Multiparous & 61.5 & 61.5 & - \\
BCS & $\leq 3.0$ & 17.3 & 13.5 & 0.59 \\
& $>3.0$ & 82.7 & 86.5 & - \\
VLS & 0 & 36.5 & 34.6 & 0.97 \\
& 1 & 34.6 & 36.5 & - \\
Abortion & 2 & 28.9 & 28.9 & - \\
& Yes & 3.9 & 11.5 & 0.14 \\
Dystocia & No & 96.2 & 88.5 & - \\
& Yes & 82.7 & 69.2 & 0.11 \\
Twins & No & 17.3 & 30.8 & - \\
& Yes & 11.5 & 13.5 & 0.77 \\
Stillbirth & No & 88.5 & 86.5 & - \\
\multirow{2}{*}{ RP } & Yes & 1.9 & 5.8 & 0.31 \\
& No & 98.1 & 94.2 & - \\
& Yes & 13.5 & 21.2 & 0.30 \\
& No & 86.5 & 78.9 & - \\
\hline
\end{tabular}

${ }^{1} \mathrm{CM}$ received daily intrauterine infusion of $8 \mathrm{~g}$ of chitosan microparticles dissolved in $40 \mathrm{~mL}$ of sterile water for $5 \mathrm{~d}$, starting at 1 DIM (24 $\mathrm{h}$ after calving); CON received daily intrauterine infusion of $40 \mathrm{~mL}$ of sterile water for $5 \mathrm{~d}$, starting at 1 DIM.

${ }^{2} \mathrm{VLS}=$ vulvovaginal laceration score: $0=$ no laceration; $1=$ laceration less than $2 \mathrm{~cm}$ at dorsal commissure of the vulva, at the lateral walls of the vulva/vagina, or both; $2=$ laceration greater than $2 \mathrm{~cm}$ at dorsal commissure of the vulva, at the lateral walls of the vulva/ vagina, or both; $\mathrm{RP}=$ retained placenta, failure to release the placenta within $24 \mathrm{~h}$ of parturition.

\section{Blood Sampling, and NEFA, BHB, and Haptoglobin Measurement}

Blood samples were collected by venipuncture of the tail vessels using evacuated tubes containing EDTA as the anticoagulant at 4, 7, 10, and 14 DIM. Blood samples were placed on ice until processing. Within 6 $\mathrm{h}$ of collection, samples were centrifuged and plasma was harvested and frozen at $-80^{\circ} \mathrm{C}$ until analysis. Commercial kits were used to determine plasma concentrations of NEFA (NEFA-C kit; Wako Diagnostics Inc., Richmond, VA; as modified by Johnson and Peters, 1993) and BHB (Wako Autokit 3-HB; Wako Diagnostics Inc.) as previously reported (Martinez et al., 2012). Inter- and intraassay coefficients of variation were 6.3 and $4.5 \%$ for NEFA, and 8.5 and $3.6 \%$ for BHB, respectively. Plasma concentration of haptoglobin was determined using a colorimetric method based on peroxidase activity as previously described (Cooke and Arthington, 2013). Inter- and intraassay coefficients of variation were 3.2 and $9.0 \%$.

\section{Animal Evaluation and Metritis Diagnosis}

Evaluation for the presence of vulvovaginal laceration was performed at enrollment and scored as pre- 
viously described: vulvovaginal laceration score $0=$ no laceration; 1 = laceration less than $2 \mathrm{~cm}$ at dorsal commissure of the vulva, at the lateral walls of the vulva/vagina, or both; 2 = laceration greater than 2 $\mathrm{cm}$ at dorsal commissure of the vulva, at the lateral walls of the vulva/vagina, or both (Vieira-Neto et al., 2016). Body condition was also scored at enrollment using a scoring system from 1 (emaciated) to 5 (obese) as previously described (Ferguson et al., 1994). Rectal temperature was measured daily, at the same time each day, up to 5 DIM, and then at 7, 10, and 14 DIM, using an electronic thermometer (GLA Agricultural Products, San Luis Obispo, CA). Individual milk production was recorded daily and was later retrieved for the first 30 DIM from the farm management software (PCDart, Dairy Records Management Systems, Raleigh, NC).

Uterine discharge was retrieved from the vagina using the Metricheck device (Simcro, Hamilton, New
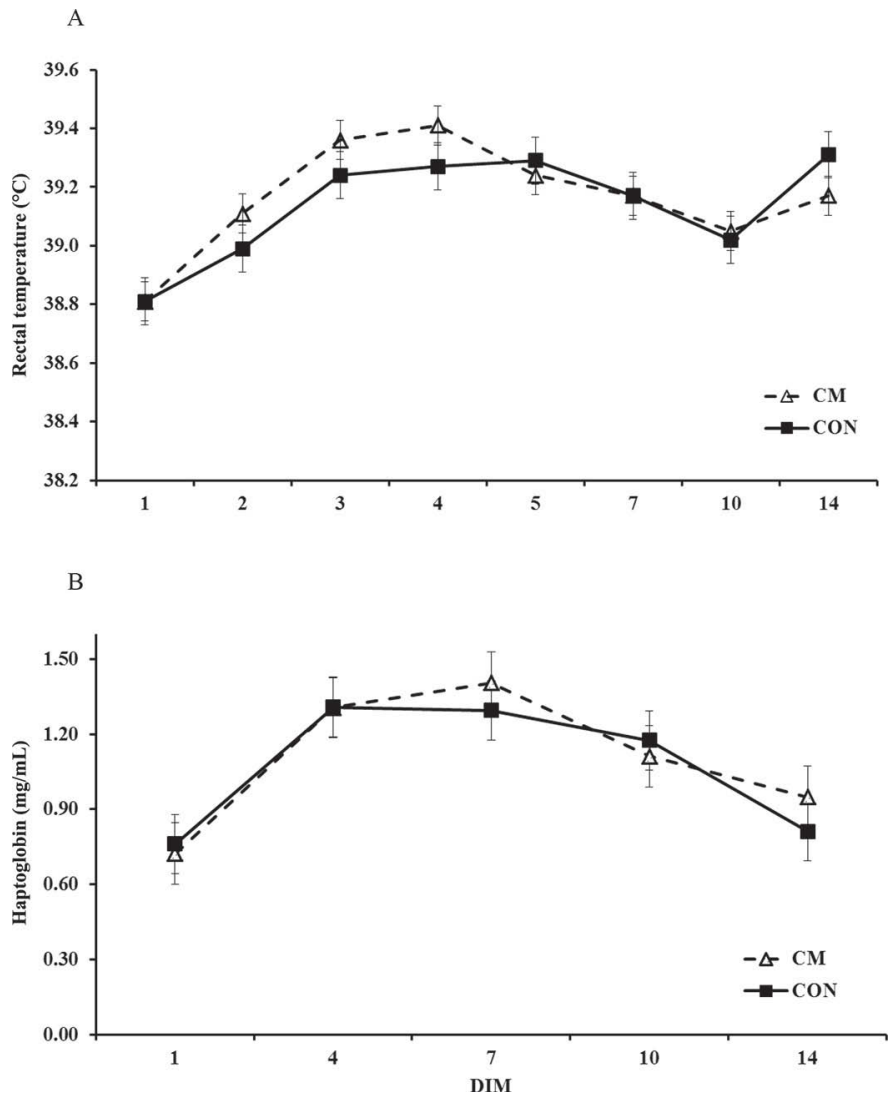

Figure 1. Least squares means $( \pm \mathrm{SE})$ for rectal temperature $(\mathrm{A})$ and plasma concentrations of haptoglobin (B). The CM group ( $\mathrm{n}=$ 52 ; open triangle-dashed line) received daily intrauterine infusion of 8 $\mathrm{g}$ of chitosan microparticles dissolved in $40 \mathrm{~mL}$ of sterile water for 5 $\mathrm{d}$, starting at 1 DIM (24 h after calving); CON ( $=52$; solid square, solid line) received daily intrauterine infusion of $40 \mathrm{~mL}$ of sterile water for $5 \mathrm{~d}$, starting at 1 DIM. Rectal temperature: Treatment (TRT), $P$ $=0.61$; DIM,$P<0.001$; TRT $\times$ DIM,$P=0.59$. Haptoglobin: TRT, $P=0.66 ;$ DIM,$P<0.001 ;$ TRT $\times$ DIM, $P=0.62$.
Zealand) at 4, 7, 10, and 14 DIM. The uterine discharge was scored as previously described: $1=$ clear or translucent mucus; 2 = not fetid, normal lochia (viscous; red, brown, or clear); 3 = not fetid; thick mucus; cloudy, clearing, or clear; $4=$ not fetid; may be purulent, mucopurulent, or chocolate brown; and $5=$ watery, reddish or brownish color of fetid discharge (Chenault et al., 2004). Metritis was defined as a score of 5 regardless of rectal temperature. The uterine discharge was collected, placed on ice, and $\mathrm{pH}$ was measured in the laboratory using a $\mathrm{pH}$ meter $(\mathrm{pH} / \mathrm{Ion} 510$, Oakton Instruments, Vernon Hills, IL).

\section{Masking}

Because the CM solution and sterile water had different colors, and because uterine infusion and uterine discharge evaluation were performed at the same time at 4 DIM, the investigators were not masked at 4 DIM. Nonetheless, the investigators were unaware of group assignment at the evaluations at 7, 10, and 14 DIM. Farm personnel were unaware of group assignment.

\section{Statistical Analysis}

Continuous outcomes such as rectal temperature, plasma haptoglobin, NEFA, and BHB concentrations, and uterine $\mathrm{pH}$ were analyzed by ANOVA for repeated measures using the MIXED procedure of SAS (version 9.4; SAS Institute Inc., Cary, NC). Outcomes were analyzed as repeated measures. Models included the fixed effects of treatment (CM or CON), DIM $(1,4,7,10$, and 14), dystocia (yes or no), RP (yes or no), twins, stillbirth or abortion (yes or no), parity (primiparous or multiparous), BCS $(\leq 3.0$ or $>3.0)$, laceration score $(0$ or $\geq 1)$, the interaction between treatment and DIM, and cow nested within treatment as the random effect. Interactions between treatment and other significant covariates were also tested. Compound symmetry covariance structure resulted in the smallest Akaike information criterion; therefore, it was used in the repeated measures analysis. Evaluation of normality of the residuals was performed in SAS by inspection of standardized residuals plotted against predicted values. Plasma NEFA, BHB, and haptoglobin had to be log transformed, and were back transformed for data presentation. Pearson correlations between rectal temperature and plasma haptoglobin and between plasma NEFA and BHB were tested using the CORR procedure of SAS.

The main dichotomous outcome of interest was development of metritis up to $4,7,10$, and 14 DIM. Cumulative incidence was calculated as the number of cases from calving until 4, 7, 10, or 14 DIM divided 
Table 2. Overall least squares means $( \pm \mathrm{SE})$ results for the effects of parity and metritis on $\mathrm{pH}$, haptoglobin, nonesterified fatty acids (NEFA), BHB, and milk yield

\begin{tabular}{|c|c|c|c|c|}
\hline Outcome $^{1}$ & Variable & Level $^{2}$ & Value & $P$-value \\
\hline \multirow[t]{4}{*}{ Rectal temperature $\left({ }^{\circ} \mathrm{C}\right)$} & Metritis & Yes & $39.15 \pm 0.03$ & 0.88 \\
\hline & & No & $39.16 \pm 0.05$ & \\
\hline & Parity & Multiparous & $39.01 \pm 0.03$ & $<0.001$ \\
\hline & & Primiparous & $39.30 \pm 0.05$ & \\
\hline \multirow[t]{4}{*}{ Haptoglobin $(\mathrm{mg} / \mathrm{mL})$} & Metritis & Yes & $1.23 \pm 0.06$ & $<0.001$ \\
\hline & & No & $0.95 \pm 0.04$ & \\
\hline & Parity & Multiparous & $1.02 \pm 0.04$ & 0.07 \\
\hline & & Primiparous & $1.14 \pm 0.06$ & \\
\hline \multirow[t]{4}{*}{ NEFA (mmol/L) } & Metritis & Yes & $0.64 \pm 0.03$ & 0.80 \\
\hline & & No & $0.63 \pm 0.05$ & \\
\hline & Parity & Multiparous & $0.69 \pm 0.03$ & 0.02 \\
\hline & & Primiparous & $0.57 \pm 0.04$ & \\
\hline \multirow[t]{4}{*}{$\mathrm{BHB}(\mathrm{mmol} / \mathrm{L})$} & Metritis & Yes & $0.64 \pm 0.03$ & 0.05 \\
\hline & & No & $0.54 \pm 0.04$ & \\
\hline & Parity & Multiparous & $0.74 \pm 0.03$ & $<0.001$ \\
\hline & & Primiparous & $0.44 \pm 0.04$ & \\
\hline \multirow[t]{4}{*}{ Milk (kg/d) } & Metritis & Yes & $27.39 \pm 0.77$ & $<0.001$ \\
\hline & & No & $33.00 \pm 1.18$ & \\
\hline & Parity & Multiparous & $32.39 \pm 0.82$ & 0.001 \\
\hline & & Primiparous & $27.99 \pm 1.10$ & \\
\hline \multirow[t]{4}{*}{ Uterine discharge $\mathrm{pH}$} & Metritis & Yes & $6.84 \pm 0.03$ & 0.003 \\
\hline & & No & $6.97 \pm 0.02$ & \\
\hline & Parity & Multiparous & $6.86 \pm 0.02$ & 0.56 \\
\hline & & Primiparous & $6.88 \pm 0.03$ & \\
\hline
\end{tabular}

by the total number of cows enrolled in each group. Two cows died with toxic metritis (1 from CM and 1 from $\mathrm{CON}$ ) and 4 were sold after a diagnosis of metritis ( 1 from $\mathrm{CM}$ and 3 from CON). These cows were not excluded from the analysis. Incidence of metritis up to 4, 7, 10, and 14 DIM was analyzed by logistic regression using the LOGISTIC procedure of SAS (version 9.4; SAS Institute Inc., Cary, NC). The model used was similar to the one described previously but without DIM or random effects. Backward elimination was used for final model selection. Variables were excluded when $P>0.10$ using the Wald statistic criterion. Descriptive statistics proportions were compared by chi-square or Fisher's exact test using the FREQ procedure of SAS. Differences with $P \leq 0.05$ were considered significant and differences with $0.05<P \leq 0.10$ were considered a tendency toward statistical significance.

\section{RESULTS}

\section{Descriptive Statistics}

The distribution of risk factors in each group is shown in Table 1. No significant differences were found between the treatment groups in any of the risk factors evaluated.

\section{Continuous Outcomes}

Rectal Temperature. No effect was found of treatment or interaction between treatment and DIM $(P=$ $0.59)$ on rectal temperature $(\mathrm{CM} 39.17 \pm 0.04$ vs. CON $39.14 \pm 0.04^{\circ} \mathrm{C} ; P=0.61$; Figure $\left.1 \mathrm{~A}\right)$. Days in milk affected $(P<0.001)$ rectal temperature with rectal temperature increasing from 1 to 4 DIM, then decreasing steadily until 10 DIM, before increasing again at 14 DIM (Figure 1A). Primiparous cows had greater rectal temperature than multiparous cows $(39.30 \pm 0.05$ vs $39.01 \pm 0.03 ; P<0.001$; Table 2).

Haptoglobin. Treatment and interaction between treatment and DIM had no effect $(P=0.62)$ on plasma haptoglobin concentration $(\mathrm{CM} 1.10 \pm 0.05$ vs. CON $1.07 \pm 0.05 \mathrm{mmol} / \mathrm{L} ; P=0.66$; Figure 1B). Days in milk had an effect $(P<0.001)$ on plasma haptoglobin in which plasma haptoglobin concentration increased from 1 to 4 DIM, remained high until 7 DIM, then decreased steadily until 14 DIM (Figure 1B). Metritic cows had greater plasma haptoglobin concertation than 
cows without metritis $(1.23 \pm 0.03$ vs. $0.95 \pm 0.06 \mathrm{mg} /$ $\mathrm{mL} ; P<0.001$; Table 2). Primiparous cows tended to have greater plasma haptoglobin concentration than multiparous cows $(1.14 \pm 0.05$ vs. $1.02 \pm 0.04 \mathrm{mg} / \mathrm{mL}$; $P=0.07$; Table 2 ).

NEFA. Treatment had no effect on plasma NEFA concentration $(\mathrm{CM} 0.64 \pm 0.04$ vs. CON $0.63 \pm 0.04$ $\mathrm{mmol} / \mathrm{L} ; P=0.87$; Figure $2 \mathrm{~A})$. An interaction was observed between treatment and DIM $(P=0.02)$ in which cows treated with $\mathrm{CM}$ had lower NEFA concentration at 10 DIM than CON cows $(0.46 \pm 0.06$ vs. $0.64 \pm$ $0.06 \mathrm{mmol} / \mathrm{L} ; P=0.03$; Figure $2 \mathrm{~A})$. Days in milk had an effect $(P<0.001)$ on plasma NEFA concentration in which plasma NEFA increased from 1 DIM until 4 DIM, then decreased steadily until 14 DIM (Figure 2A). Multiparous cows had a greater NEFA concentration than primiparous cows $(0.69 \pm 0.03$ vs. $0.57 \pm 0.04$ $\mathrm{mmol} / \mathrm{L} ; P=0.02$; Table 2 ).
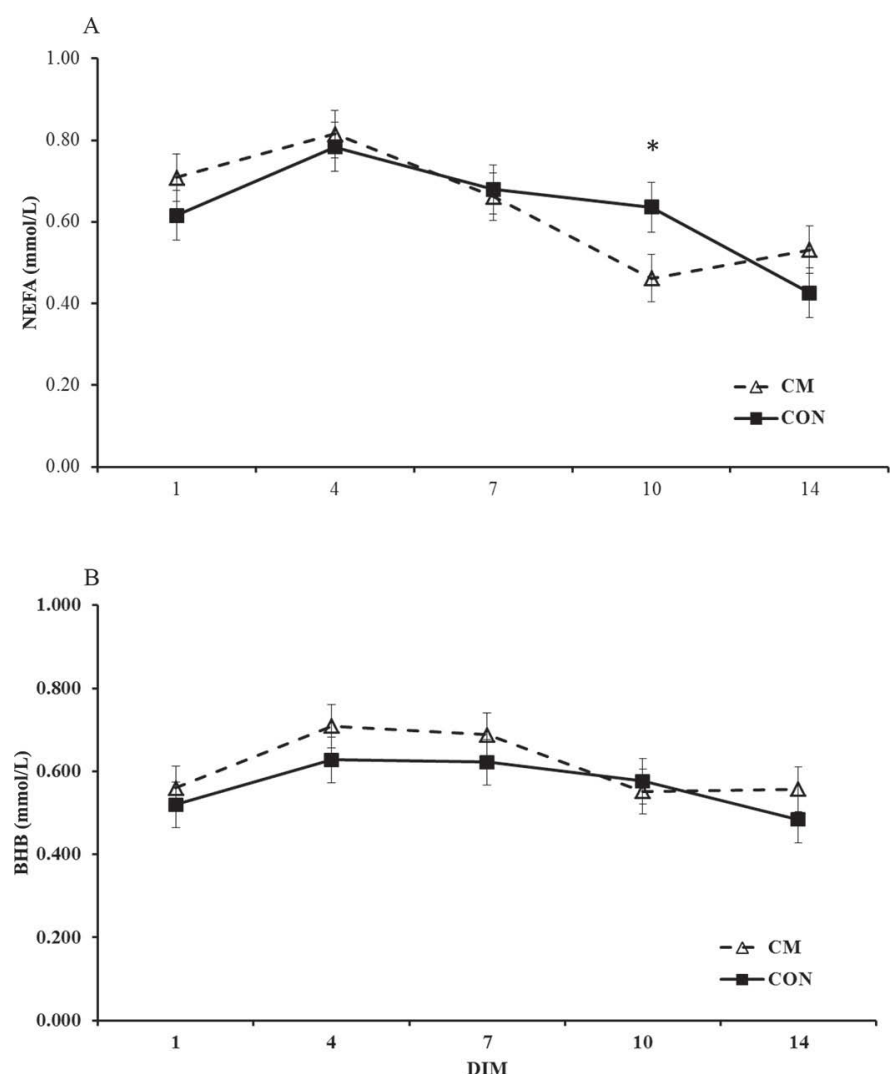

Figure 2. Least squares means $( \pm \mathrm{SE})$ of plasma concentrations for NEFA (A) and BHB (B). The CM group ( $\mathrm{n}=52$; open triangledashed line) received daily intrauterine infusion of $8 \mathrm{~g}$ of chitosan microparticles dissolved in $40 \mathrm{~mL}$ of sterile water for $5 \mathrm{~d}$, starting at 1 DIM (24 h after calving); CON ( $\mathrm{n}=52$; solid square, solid line) received daily intrauterine infusion of $40 \mathrm{~mL}$ of sterile water for $5 \mathrm{~d}$, starting at 1 DIM. NEFA: Treatment (TRT), $P=0.87$; DIM, $P<$ 0.001 ; TRT $\times$ DIM,$P=0.02 ;{ }^{*} P=0.01$. BHB: TRT, $P=0.26$; DIM, $P<0.01 ;$ TRT $\times$ DIM,$P=0.81$.
$\boldsymbol{B H} \boldsymbol{B}$. Treatment and interaction between treatment and DIM had no effect $(P=0.81)$ on plasma BHB concentration $(\mathrm{CM} 0.61 \pm 0.04$ vs. $\mathrm{CON} 0.57 \pm 0.04$ $\mathrm{mmol} / \mathrm{L} ; P=0.26$; Figure 2B). Days in milk had an effect $(P<0.001)$ on plasma BHB concentration in which plasma BHB increased from 1 DIM until 4 DIM, remained high until 7 DIM, then decreased steadily until 14 DIM (Figure 2B). Metritic cows had greater plasma BHB concentration than cows without metritis $(0.64 \pm 0.02$ vs. $0.54 \pm 0.03 \mathrm{mmol} / \mathrm{L} ; P=0.05$; Table $2)$. Multiparous cows had greater plasma BHB concentration than primiparous cows $(0.74 \pm 0.04$ vs. $0.44 \pm$ $0.03 \mathrm{mmol} / \mathrm{L} ; P<0.001$; Table 2).

Milk Production. Treatment and interaction between treatment and DIM had no effect $(P=0.27)$ on milk yield in the first 30 DIM (CM $30.26 \pm 0.92$ vs. CON $30.12 \pm 0.97 \mathrm{~kg} / \mathrm{d} ; P=0.91$; Figure 3$)$. Days in milk had an effect $(P<0.001)$ on milk yield in which milk yield increased abruptly from 1 to 2 DIM, then increased steadily until 30 DIM (Figure 3). Metritic cows produced less milk in the first 30 DIM than cows without metritis $(27.39 \pm 0.77$ vs. $33.00 \pm 1.18 \mathrm{~kg} / \mathrm{d}$; $P<0.001$; Table 2). Multiparous cows produced more milk than primiparous cows $(32.39 \pm 0.82$ vs. $27.99 \pm$ $1.10 \mathrm{~kg} / \mathrm{d} ; P<0.001$; Table 2).

Uterine Discharge $\boldsymbol{p H}$. Treatment affected uterine discharge $\mathrm{pH}$, and cows receiving $\mathrm{CM}$ had greater uterine discharge $\mathrm{pH}$ than $\mathrm{CON}$ cows $(6.91 \pm 0.03$ vs. $6.83 \pm 0.03 ; P=0.05$; Figure 4). Although no interaction was found between treatment and time $(P=0.55)$, uterine $\mathrm{pH}$ was greater for the $\mathrm{CM}$ group than $\mathrm{CON}$ only at $7 \mathrm{DIM}(7.03 \pm 0.05$ vs. $6.88 \pm 0.05 ; P=0.02$; Figure 5$)$. There was an effect of DIM $(P<0.001)$ on uterine discharge $\mathrm{pH}$ in which uterine discharge $\mathrm{pH}$ was lower at 10 and 14 DIM than at 4 and 7 DIM (Figure 4). Metritic cows had lower uterine discharge $\mathrm{pH}$ than cows without metritis $(6.84 \pm 0.02$ vs. $6.97 \pm 0.03 ; P$ $=0.003$; Table 2).

\section{Correlations}

Rectal temperature was positively correlated with plasma haptoglobin concentration $(\mathrm{r}=0.15 ; P<$ 0.001). Plasma NEFA was positively correlated with plasma BHB concentration $(\mathrm{r}=0.64 ; P<0.001)$.

\section{Dichotomous Outcome: Metritis}

The cumulative incidence of metritis was evaluated up to $4,7,10$, and 14 DIM (Figure 5). Treatment with CM resulted in decreased incidence of metritis up to 7 DIM compared with CON (46.2 vs. $65.4 \% ; P=0.05$ ); however, no differences were found at 4 (11.5 vs. $17.3 \%$; $P=0.41), 10(61.5$ vs. $73.1 \% ; P=0.20)$, and 14 DIM 


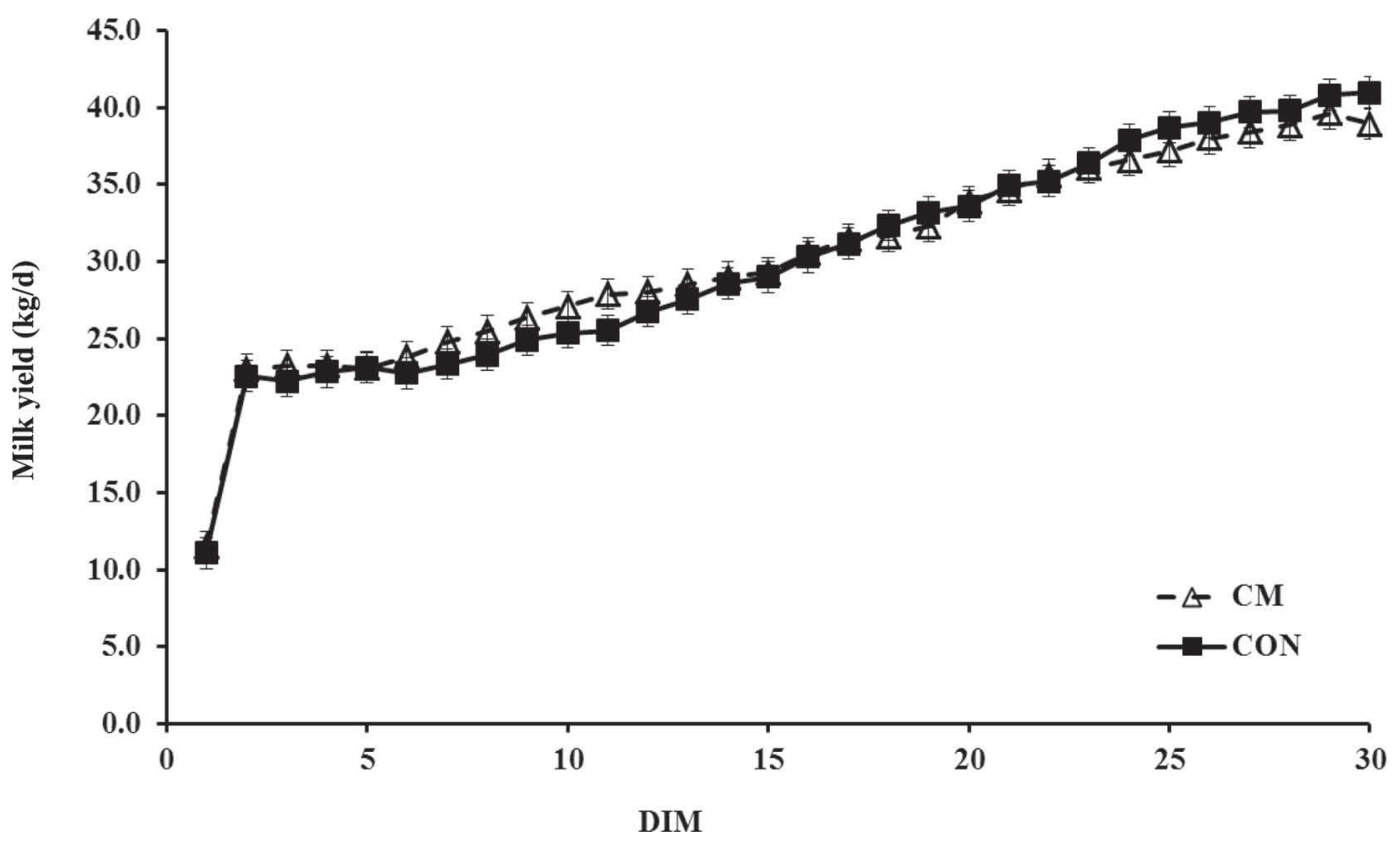

Figure 3. Least squares means $( \pm \mathrm{SE})$ for milk yield. The CM group $(\mathrm{n}=52$; open triangle-dashed line) received daily intrauterine infusion of $8 \mathrm{~g}$ of chitosan microparticles dissolved in $40 \mathrm{~mL}$ of sterile water for $5 \mathrm{~d}$, starting at $1 \mathrm{DIM}$ ( $24 \mathrm{~h}$ after calving); CON (n $=52 ;$ solid square, solid line) received daily intrauterine infusion of $40 \mathrm{~mL}$ of sterile water for $5 \mathrm{~d}$, starting at $1 \mathrm{DIM}$. Treatment $(\mathrm{TRT}), P=0.91 ; \mathrm{DIM}, P<0.001$; TRT $\times$ DIM, $P=0.27$.

(63.5 vs. $73.1 \% ; P=0.28)$ for $\mathrm{CM}$ versus $\mathrm{CON}$, respectively.

\section{DISCUSSION}

This experiment was designed to evaluate the clinical response after intrauterine administration of $\mathrm{CM}$ in

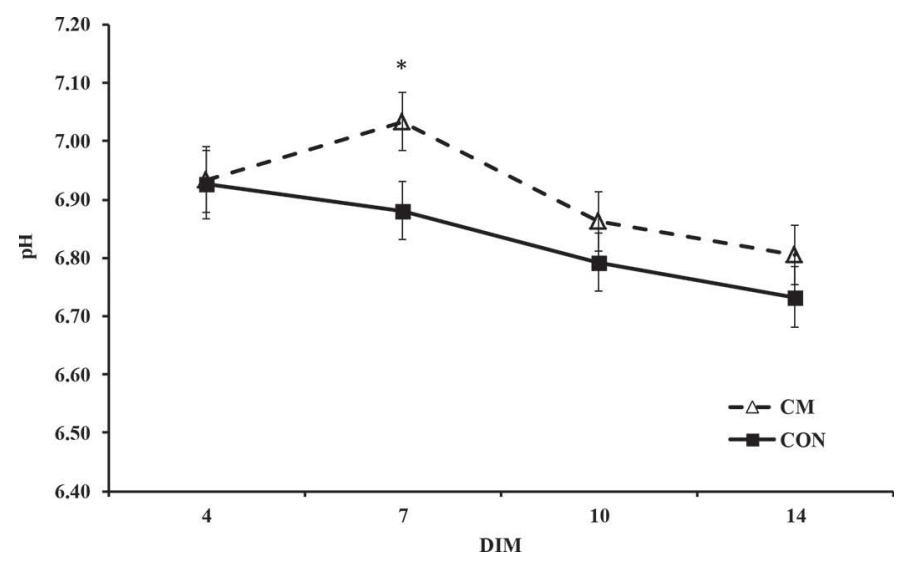

Figure 4. Least squares means $( \pm \mathrm{SE})$ for uterine fluid $\mathrm{pH}$. The $\mathrm{CM}$ group $(\mathrm{n}=52$; open triangle-dashed line) received daily intrauterine infusion of $8 \mathrm{~g}$ of chitosan microparticles dissolved in $40 \mathrm{~mL}$ of sterile water for $5 \mathrm{~d}$, starting at 1 DIM (24 h after calving); CON ( $\mathrm{n}=52$; solid square, solid line) received daily intrauterine infusion of $40 \mathrm{~mL}$ of sterile water for $5 \mathrm{~d}$, starting at 1 DIM. Treatment (TRT), $P=0.05$; DIM, $P<0.01$; TRT $\times$ DIM, $P=0.55 . * P=0.03$. dairy cows and to determine the effect of intrauterine administration of $\mathrm{CM}$ on the incidence of metritis in cows at risk for metritis. Intrauterine administration of CM could potentially lead to an inflammatory response, which could lead to a decrease in DMI, an increase in lipid mobilization, an increase in ketone body production, and a decrease in milk production (Kushibiki et al., 2003). Nonetheless, no evidence was found that intrauterine $\mathrm{CM}$ led to an overt inflammatory response; rectal temperature, plasma haptoglobin, plasma NEFA, plasma BHB, and milk production were unaffected by $\mathrm{CM}$ administration. Therefore, intrauterine administration of $\mathrm{CM}$ as done here can be considered safe for the cow.

As expected, cows with metritis had increased concentrations of haptoglobin and BHB, and decreased milk yield. An increase in plasma haptoglobin concentration is expected in cows with metritis in response to pro-inflammatory cytokines such as tumor necrosis factor- $\alpha(\mathrm{TNF} \alpha)$ and IL-6 that are produced in the presence of tissue damage or LPS release by gram-negative bacteria (Nakagawa-Tosa et al., 1995; Kushibiki et al., 2003). In agreement with our findings, previous studies have reported that plasma haptoglobin concentration was increased in cows with metritis compared with healthy cows (Huzzey et al., 2009; Galvão et al., 2010). Likewise, others have also reported higher BHB concentration for cows with metritis compared with 
healthy cows, which was a consequence of decreased DMI and increased lipid mobilization in the form of NEFA (Hammon et al., 2006; Galvão et al., 2010). It is not clear why plasma BHB concentration increased without an increase in NEFA, given the high correlation between NEFA and BHB. Nonetheless, some researchers have reported similar findings in the first week postpartum (Giuliodori et al., 2013). The decrease in milk yield in metritic cows agrees with previous observational studies (Huzzey et al., 2007; Giuliodori et al., 2013), and studies that challenged cows with LPS or TNFo (Kushibiki et al., 2003; Waldron et al., 2003). The decrease in milk yield was primarily due to a decrease in DMI, although a decrease in plasma IGF-1 was also observed by Kushibiki et al. (2003).

In regards to our second objective, CM were shown to be effective in reducing the cumulative incidence of metritis up to 7 DIM; however, the differences were not sustained until the end of the observation period. The loss of effectiveness of CM in reducing metritis after 7 DIM may be due to the possibility that the uterine bacterial load increased after d 5 of treatment. Herein, we measured uterine $\mathrm{pH}$ as a proxy for uterine bacterial load, and observed that CM-treated cows had higher uterine $\mathrm{pH}$ at $7 \mathrm{DIM}$ but not afterward. Intrauterine anaerobic fermentation of carbohydrates and AA by bacteria such as Bacteroides spp., E. coli, F. necrophorum, and T. pyogenes produces acid compounds such as short-chain fatty acids as end products, therefore lowering the $\mathrm{pH}$ of a medium (Cuchural and Tally, 1982). We postulate that a lower uterine $\mathrm{pH}$ in the $\mathrm{CON}$ group could have been caused by a greater bacterial load com- pared with the CM group. In fact, cows that developed metritis within 14 DIM had a lower uterine $\mathrm{pH}$ than cows without metritis. Due to budgetary constraints, we were not able to directly measure uterine bacterial contamination; however, this should be performed in future studies to confirm our hypothesis that CM reduced bacterial load up to 7 DIM. Administration of ceftiofur to cows with risk factors similar to the ones used for inclusion in this study has been shown to be effective in reducing the incidence of metritis up to 14 DIM in some studies (Risco and Hernandez, 2003; McLaughlin et al., 2013) but not all (Dubuc et al., 2011). In this study, CM-treated cows had numerically higher incidence of dystocia; however, vaginal laceration, which is a stronger predictor of metritis (VieiraNeto et al., 2016) was very similar to control cows. In addition, there was no evidence that individual risk factors differentially affected the incidence of metritis because they were all included in the analyses and none of them were significant.

It is also possible that a higher dose of CM is needed to eliminate a wider range of uterine pathogens. The dose of CM used in the present experiment was based on $E$. coli reduction demonstrated previously (Jeon et al., 2014). Although E. coli plays an important role in the development of metritis (Bicalho et al., 2010; Sheldon et al., 2010), recent studies have shown that other bacterial strains such as Bacteroides spp. and Fusobacterium spp. are more abundant in metritic cows than Escherichia spp. (Jeon et al., 2015); therefore, other bacterial species should be tested in the future. Additionally, once CM are attached to a bacterial wall

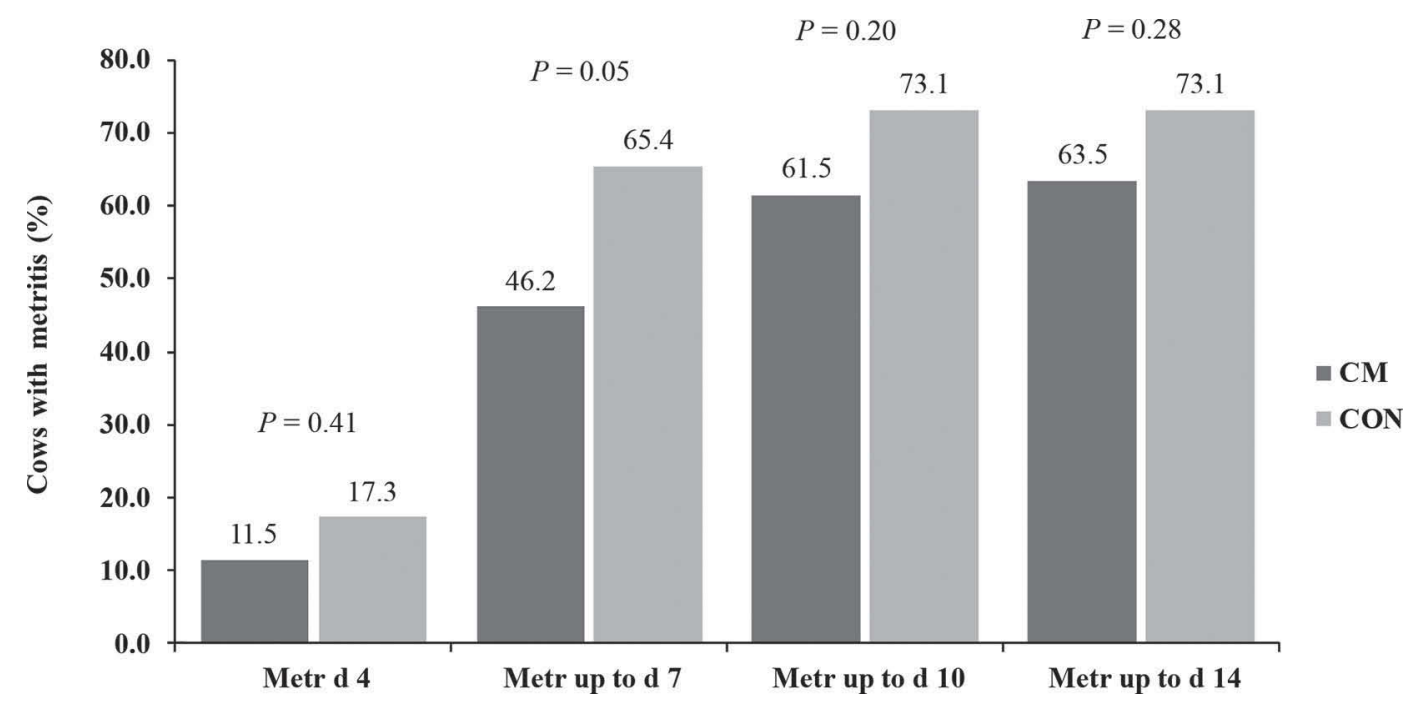

Figure 5. Incidence of metritis. The CM group $(\mathrm{n}=52)$ received daily intrauterine infusion of $8 \mathrm{~g}$ of chitosan microparticles dissolved in 40 $\mathrm{mL}$ of sterile water for $5 \mathrm{~d}$, starting at $1 \mathrm{DIM}(24 \mathrm{~h}$ after calving); CON $(\mathrm{n}=52)$ received daily intrauterine infusion of $40 \mathrm{~mL}$ of sterile water for $5 \mathrm{~d}$, starting at 1 DIM. 
it is no longer available to attach to another bacterium (Sudarshan et al., 1992), and constant shifts of bacterial contamination and recontamination (Griffin et al., 1974) that occurs during the postpartum period could also explain the elevation of metritis incidence in the CM group after 7 DIM. Finally, although CM were partially effective in preventing metritis, that did not translate into higher milk yield. Nonetheless, this has also been the case even when the prophylactic treatment with long-acting ceftiofur was fully effective in reducing the incidence of metritis (McLaughlin et al. 2013). Therefore, the prevention of metritis may be more important to improve cow welfare than to increase economic return.

\section{CONCLUSIONS}

Intrauterine administration of $8 \mathrm{~g}$ of $\mathrm{CM}$ did not alter clinical parameters of cows at risk for metritis. Furthermore, CM treatment decreased the cumulative incidence of metritis up to 7 DIM. Nonetheless, the duration of treatment may have to be extended, and dosage may have to be revised to maintain differences in the incidence of metritis after 7 DIM. Results from this study indicate that $\mathrm{CM}$ may be a viable alternative to traditional antibiotics for the prevention of metritis.

\section{ACKNOWLEDGMENTS}

The authors thank the owner, Don Bennink, and the staff of North Florida Holsteins in Bell, Florida, for allowing us the use of their cows for this study. We also thank the Southeast Milk Inc. Milk Check-Off program and the USDA-NIFA-HATCH program (Accession No. 0229910) administered by the College of Veterinary Medicine at University of Florida for providing funding for this project.

\section{REFERENCES}

Bhandari, M., H. Lochner, and P. Tornetta 3rd.. 2002. Effect of continuous versus dichotomous outcome variables on study power when sample sizes of orthopaedic randomized trials are small. Arch. Orthop. Trauma Surg. 122:96-98.

Bicalho, M. L., V. S. Machado, G. Oikonomou, R. O. Gilbert, and R. C. Bicalho. 2012. Association between virulence factors of Escherichia coli, Fusobacterium necrophorum, and Arcanobacterium pyogenes and uterine diseases of dairy cows. Vet. Microbiol. 157:125-131.

Bicalho, R. C., V. S. Machado, M. L. Bicalho, R. O. Gilbert, A. G. Teixeira, L. S. Caixeta, and R. V. Pereira. 2010. Molecular and epidemiological characterization of bovine intrauterine Escherichia coli. J. Dairy Sci. 93:5818-5830.

Chenault, J. R., J. F. McAllister, S. T. Chester, K. J. Dame, F. M. Kausche, and E. J. Robb. 2004. Efficacy of ceftiofur hydrochloride sterile suspension administered parenterally for the treatment of acute postpartum metritis in dairy cows. J. Am. Vet. Med. Assoc. 224:1634-1639.
Cooke, R. F., and J. D. Arthington. 2013. Concentrations of haptoglobin in bovine plasma determined by ELISA or a colorimetric method based on peroxidase activity. J. Anim. Physiol. Anim. Nutr. (Berl.) 97:531-536.

Courvalin, P. 2008. Predictable and unpredictable evolution of antibiotic resistance. J. Intern. Med. 264:4-16.

Cuchural, G., and F. P. Tally. 1982. Factors affecting the choice of antimicrobial therapy for anaerobic infection. J. Antimicrob. Chemother. 10:11-22.

Curtis, C. R., H. N. Erb, C. J. Sniffen, R. D. Smith, and D. S. Kronfeld. 1985. Path analysis of dry period nutrition, postpartum metabolic and reproductive disorders, and mastitis in Holstein cows. J. Dairy Sci. 68:2347-2360.

Dubuc, J., T. F. Duffield, K. E. Leslie, J. S. Walton, and S. J. Leblanc. 2011. Randomized clinical trial of antibiotic and prostaglandin treatments for uterine health and reproductive performance in dairy cows. J. Dairy Sci. 94:1325-1338.

Ferguson, J. D., D. T. Galligan, and N. Thomsen. 1994. Principal descriptors of body condition score in Holstein cows. J. Dairy Sci. 77:2695-2703

Galvão, K. N., M. J. Flaminio, S. B. Brittin, R. Sper, M. Fraga, L. Caixeta, A. Ricci, C. L. Guard, W. R. Butler, and R. O. Gilbert. 2010. Association between uterine disease and indicators of neutrophil and systemic energy status in lactating Holstein cows. J. Dairy Sci. 93:2926-2937.

Gier, H. T., and G. B. Marion. 1968. Uterus of the cow after parturition: Involutional changes. Am. J. Vet. Res. 29:83-96.

Giuliodori, M. J., R. Magnasco, D. Becu-Villalobos, I. Lacau-Mengido, C. A. Risco, and R. de la Sota. 2013. Metritis in dairy cows: Risk factors and reproductive performance. J. Dairy Sci. 96:3621-3631.

Griffin, J. F. T., P. J. Hartigan, and W. R. Nunn. 1974. Non-specific uterine infection and bovine fertility. Theriogenology 1:91-106.

Hammon, D. S., I. M. Evjen, T. R. Dhiman, J. P. Goff, and J. L. Walters. 2006. Neutrophil function and energy status in Holstein cows with uterine health disorders. Vet. Immunol. Immunopathol. 113:21-29.

Huzzey, J. M., T. F. Duffield, S. J. LeBlanc, D. M. Veira, D. M. Weary, and M. A. G. von Keyserlingk. 2009. Short communication: Haptoglobin as an early indicator of metritis. J. Dairy Sci. 92:621-625.

Huzzey, J. M., D. M. Veira, D. M. Weary, and M. A. G. von Keyserlingk. 2007. Prepartum behavior and dry matter intake identify dairy cows at risk for metritis. J. Dairy Sci. 90:3220-3233.

Jeon, S. J., M. Oh, W.-S. Yeo, K. N. Galvão, and K. C. Jeong. 2014. Underlying mechanism of antimicrobial activity of chitosan microparticles and implications for the treatment of infectious diseases. PLoS ONE 9:e92723.

Jeon, S. J., A. Vieira-Neto, M. Gobikrushanth, R. Daetz, R. D. Mingoti, A. C. B. Parize, S. L. de Freitas, A. N. L. da Costa, R. C. Bicalho, S. Lima, K. C. Jeong, and K. N. Galvão. 2015. Uterine microbiota progression from calving until establishment of metritis in dairy cows. Appl. Environ. Microbiol. 81:6324-6332.

Johnson, M. M., and J. P. Peters. 1993. Technical note: An improved method to quantify nonesterified fatty acids in bovine plasma. J. Anim. Sci. 71:753-756.

Kushibiki, S., K. Hodate, H. Shingu, Y. Obara, E. Touno, M. Shinoda, and Y. Yokomizo. 2003. Metabolic and lactational responses during recombinant bovine tumor necrosis factor-alpha treatment in lactating cows. J. Dairy Sci. 86:819-827.

Ma, Z., D. Kim, A. T. Adesogan, S. Ko, K. Galvão, and K. C. Jeong. 2016. Chitosan microparticles exert broad-spectrum antimicrobial activity against antibiotic-resistant micro-organisms without increasing resistance. ACS Appl. Mater. Interfaces 8:10700-10709.

Markusfeld, O. 1984. Factors responsible for post parturient metritis in dairy cattle. Vet. Rec. 114:539-542.

Martinez, N., C. A. Risco, F. S. Lima, R. S. Bisinotto, L. F. Greco, E. S. Ribeiro, F. Maunsell, K. Galvão, and J. E. P. Santos. 2012. Evaluation of peripartal calcium status, energetic profile, and neutrophil function in dairy cows at low or high risk of developing uterine disease. J. Dairy Sci. 95:7158-7172.

Mateus, L., L. Lopes Da Costa, F. Bernardo, and J. Robalo Silva. 2002. Influence of puerperal uterine infection on uterine involution 
and postpartum ovarian activity in dairy cows. Reprod. Domest. Anim. 37:31-35.

McLaughlin, C. L., E. P. Stanisiewski, C. A. Risco, J. E. P. Santos, G. E. Dahl, R. C. Chebel, C. LaGrow, C. Daugherty, L. Bryson, D. Weigel, J. Hallberg, and M. J. Lucas. 2013. Evaluation of ceftiofur crystalline free acid sterile suspension for control of metritis in high-risk lactating dairy cows. Theriogenology 79:725-734.

Nakagawa-Tosa, N., M. Morimatsu, M. Kawasaki, H. Nakatsuji, B. Syuto, and M. Saito. 1995. Stimulation of haptoglobin synthesis by interleukin- 6 and tumor necrosis factor, but not by interleukin-1, in bovine primary cultured hepatocytes. J. Vet. Med. Sci. $57: 219-223$

NRC. 2001. Nutrient Requirements of Dairy Cattle. 7th ed. Natl. Acad. Press, Washington, DC

Overton, M., and J. Fetrow. 2008. Economics of postpartum uterine health. Pages 39-43 in Proc. Dairy Cattle Reproduction Council Convention, Omaha, NE. Dairy Cattle Reproduction Council, Champaign, IL.

Risco, C. A., and J. Hernandez. 2003. Comparison of ceftiofur hydrochloride and estradiol cypionate for metritis prevention and reproductive performance in dairy cows affected with retained fetal membranes. Theriogenology 60:47-58.
Sheldon, I. M., and H. Dobson. 2004. Postpartum uterine health in cattle. Anim. Reprod. Sci. 82-83:295-306.

Sheldon, I. M., A. N. Rycroft, B. Dogan, M. Craven, J. J. Bromfield, A. Chandler, M. H. Roberts, S. B. Price, R. O. Gilbert, and K. W. Simpson. 2010. Specific strains of Escherichia coli are pathogenic for the endometrium of cattle and cause pelvic inflammatory disease in cattle and mice. PLoS ONE 5:e9192.

Stojkov, J., M. A. von Keyserlingk, J. N. Marchant-Forde, and D. M. Weary. 2015. Assessment of visceral pain associated with metritis in dairy cows. J. Dairy Sci. 98:5352-5361.

Sudarshan, N., D. G. Hoover, and D. Knorr. 1992. Antibacterial action of chitosan. Food Biotechnol. 6:257-272.

Vieira-Neto, A., F. S. Lima, J. E. Santos, R. D. Mingoti, G. S. Vasconcellos, C. A. Risco, and K. N. Galvão. 2016. Vulvovaginal laceration as a risk factor for uterine disease in postpartum dairy cows. J. Dairy Sci. 99:4629-4637.

Waldron, M. R., T. Nishida, B. J. Nonnecke, and T. R. Overton. 2003. Effect of lipopolysaccharide on indices of peripheral and hepatic metabolism in lactating cows. J. Dairy Sci. 86:3447-3459. 